\title{
A Compact Dual Band-notched Circular Ring Printed Monopole Antenna for Super-wideband Applications
}

\author{
Murli MANOHAR ${ }^{1}$, Rakhesh Singh KSHETRIMAYUM ${ }^{2}$, Anup Kumar GOGOI ${ }^{2}$ \\ ${ }^{1}$ Dept. of Electronics and Communications Engineering, IIIT Manipur, 795002 Imphal, India \\ ${ }^{2}$ Dept. of Electronics and Electrical Engineering, IIT Guwahati, 781039 Guwahati, India \\ murli@iiitmanipur.ac.in, krs@iitg.ernet.in, akg@iitg.ernet.in
}

Submitted January 26, 2016 / Accepted October 30, 2016

\begin{abstract}
In this article, a simple and compact dual bandnotched (DBN) super wideband (SWB) printed monopole antenna (PMA) has been proposed. The proposed antenna composed of a circular PMA, which is connected through a 50- $\Omega$ triangular tapered microstrip fed line (TTMFL) and a round-cornered finite ground plane (RCFGP). It exhibits a very wide frequency band from 1.6-25 GHz (ratio bandwidth of 15.63:1) with a voltage standing wave ratio $(V S W R) \leq 2$. By employing a U-shaped parasitic element (USPE) near the RCFGP and a T-shaped protruded stub (TSPS) inside the radiating patch, a single band-notched $(S B N)$ characteristic in the frequency band of 3.2-4.4 GHz (WiMAX/C-band) is generated. In order to realize the second band-notched function for X-band satellite communication systems (7.2-8.4 GHz), a U-shaped slot (USS) has been inserted in the RCFGP. The overall dimension of the proposed antenna is $24 \times 30 \times 0.787 \mathrm{~mm}^{3}$ and occupies a relatively small space compared to the existing DBN antennas. Good agreement has been attained between predicted and measured results.
\end{abstract}

\section{Keywords}

Dual band-notch, super wideband (SWB) antenna, triangular tapered microstrip feed line

\section{Introduction}

Nowadays there is an increasing demand of super wideband (SWB) radios in the modern wireless communication systems, owing to their extremely large bandwidth (BW) and very high data transmission rate. Printed monopole antenna (PMA) is an ideal candidate for SWB applications due to its several fascinating features such as small size, low cost, planar structure, operation over extremely large impedance BW and ease to accommodate with small space provided by hand held gadgets. Existing ultra-wideband (UWB) PMA (BW of 3.1 to $10.6 \mathrm{GHz}$ ) [1] also have features like that of SWB except that its ratio bandwidth (RB) falls short of SWB antennas and is just 3.42:1. SWB antennas should offer RB of more than $10: 1$ and were first supposedly developed by Rumsey et al. in the late 1950 and early 1960 and were called frequency-independent antennas [2].

Recently, few SWB antennas have been investigated by many researchers in the published literature [3-7]. Unfortunately, it is to be noted that some of the existing narrow-band systems such as WiMAX (3.3-3.6 GHz), C-band (3.7-4.2 GHz) and X-band satellite communication systems operating in $7.25-8.395 \mathrm{GHz}$ (for down link: 7.25-7.745 GHz and uplink: $7.9-8.395 \mathrm{GHz}$ ) may cause electromagnetic interference (EMI) to the SWB system. So, to mitigate this electromagnetic interference issue, SWB antennas with band-notched characteristics is required. Several dual band-notched (DBN) UWB antennas have been investigated by many researchers across the globe [8-13].

However, the above mentioned antennas have been designed to have notch within the UWB BW and occupy a relatively large space. But to the author's knowledge, there are no DBN SWB antennas reported in the literature. In this communication, a novel and compact DBN SWB PMA is presented. The designed antenna offers a wide impedance $\mathrm{BW}$ from 1.6 to $25 \mathrm{GHz}$ with a VSWR $\leq 2$ except in the DBN of 3.2-4.4 GHz and 7.2-8.4 GHz. The proposed antenna offers wide $\mathrm{BW}$ with $\mathrm{DBN}$ characteristics and is small in size compared to the DBN UWB antennas reported in [8-13]. By tuning the dimensions of U-shaped parasitic element (USPE) and U-shaped slot (USS), two suitable notches are obtained. Good agreement has been obtained between simulation and experimental results of the proposed DBN SWB PMA. Simulation results have been carried out with the finite element method (FEM) based commercial software Ansoft high-frequency structure simulator (HFSS).

\section{Antenna Configuration}

The configuration of the proposed DBN SWB circular ring (CR) PMA is illustrated in Fig. 1. The CR PMA is printed on the RT/Duroid 5870 substrate of thickness $t=0.787 \mathrm{~mm}$ with dielectric constant $\varepsilon_{\mathrm{r}}$ of 2.23 , which is 


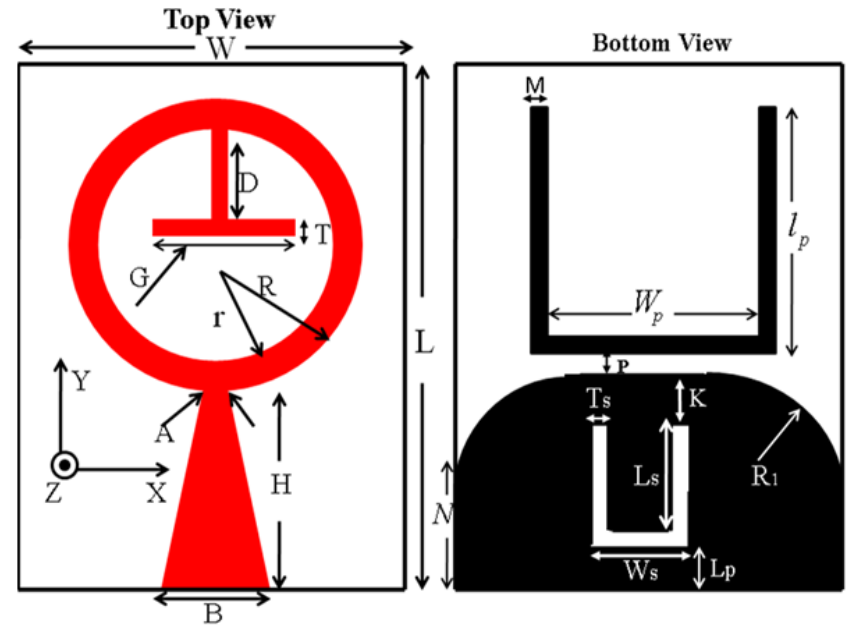

Fig. 1. Geometry of the proposed DBN SWB PMA.

excited through a $50-\Omega$ triangular tapered microstrip fed line (TTMFL). For the signal transmission, a two-hole Sub Miniature version A (SMA)-connector has been utilized. We have specifically chosen the above mentioned substrate since FR4 substrate becomes highly lossy at higher frequencies. The proposed antenna (the overall dimensions of about $24 \times 30 \times 0.787 \mathrm{~mm}^{3}$ ) consists of a CR radiating patch with a T-shaped protruded stub (TSPS) inside CR radiating patch. The rear side of the RT/Duroid substrate is composed of a round-cornered finite ground plane (RCFGP) with embedded USS and USPE, which is placed under the CR patch. The TTMFL is used for broadband impedance matching and the reflection coefficient $(|\Gamma(\theta)|)$ response of triangular taper has minima for $\beta l=2 m \pi$ where $m=1,2,3, \ldots$ and corresponding frequencies. A closed form solution of the Riccati equation for triangularly tapered feed line is given by [14]

$$
\Gamma(\theta)=\frac{1}{2} \exp \left(-j \beta l_{k}\right) \ln \left(\frac{Z_{l_{k}}}{Z_{0}}\right)\left[\frac{\sin \left(\frac{\beta l_{k}}{2}\right)}{\frac{\beta l_{k}}{2}}\right]^{2}
$$

where $\Gamma(\theta)$ is the reflection coefficient, $\beta$ is the phase constant and $l_{k}=H$ is the triangular tapered feed line length. To get the widths at the two ends of the tapered lines, method reported in [15] is followed.

The optimal dimensions of the proposed antennas are as follows: $L=30 \mathrm{~mm}, W=24 \mathrm{~mm}, \quad H=13 \mathrm{~mm}$, $A=1 \mathrm{~mm}, \quad B=3 \mathrm{~mm}, \quad G=5.5 \mathrm{~mm}, \quad D=4.5 \mathrm{~mm}$, $T=0.5 \mathrm{~mm}, \quad R=8 \mathrm{~mm}, \quad r=6 \mathrm{~mm}, \quad N=6.2 \mathrm{~mm}$, $W_{\mathrm{p}}=14.5 \mathrm{~mm}, \quad l_{\mathrm{p}}=16.5 \mathrm{~mm}, \quad M=0.5 \mathrm{~mm}, \quad p=1 \mathrm{~mm}$, $T_{\mathrm{S}}=0.2 \mathrm{~mm}, L_{\mathrm{S}}=5.2 \mathrm{~mm}, W_{\mathrm{s}}=1.5 \mathrm{~mm}, L_{\mathrm{p}}=4.5 \mathrm{~mm}$, $K=1.6 \mathrm{~mm}$ and $R_{1}=4.9 \mathrm{~mm}$. Here the optimized electrical length of the USPE $\left(U_{1}\right)$ and USS $\left(U_{2}\right)$ are set to approximately $\quad 0.5 \lambda_{\mathrm{g}} \quad$ and $\quad 0.25 \lambda_{\mathrm{g}}$, where $U_{1}=W_{\mathrm{p}}+2 l_{\mathrm{p}}+2 M, \mathrm{U}_{2}=W_{\mathrm{s}}+2 L_{\mathrm{S}}+2 T_{\mathrm{S}} . \lambda_{\mathrm{g}}$ is the guided wavelength corresponding to band notch frequencies at 3.8 and $7.8 \mathrm{GHz}$ respectively.

\section{Results and Discussions}

Figure 2 presents design evolution of the proposed SWB DBN PMA which illustrates the steps for enhancing the impedance BW as well as formation of DBN characteristics. The corresponding simulated VSWR characteristics comparison of Antennas 1-5 are shown in Fig. 3. Antenna 1 consists of a simple monopole disc connected with a rectangular feed line and rectangular finite ground plane that provides BW of 2.8-9.9 GHz (refer to Fig. 3). To improve the impedance BW of Antenna 1, the rectangular feed line has been replaced by a triangular tapered microstrip fed line (TTMFL) in Antenna 2 and it offers wide BW of $1.6-23.5 \mathrm{GHz}$ without increasing the dimension as depicted in Fig. 3.

To further increase the BW of Antenna 2, we modified the rectangular ground plane of Antenna 2 into roundcornered finite ground plane (RCFGP) in Antenna 3. In Antenna 3, the ground plane also participates in radiation [16-17], additional resonance is excited at the higher frequencies and hence the impedance matching characteristics tend to improve over the entire band, resulting in an extremely large BW of $1.6-25 \mathrm{GHz}$ or above. It is capable of supporting SWB radios without increasing the antenna dimensions. Now to generate the first band-stop (BS) characteristics for X-band satellite communication systems (7.2-8.4 GHz), a U-shaped slot (USS) is inserted in the RCFGP (Antenna 4). By employing a U-shaped parasitic element (USPE) on the rear side of the substrate and an inverted T-shaped protruded stub (TSPS) within the circular ring (CR) shaped radiation patch we generate the second BS characteristics for WiMAX/C-band (3.2-4.4 GHz) application (Antenna 5).

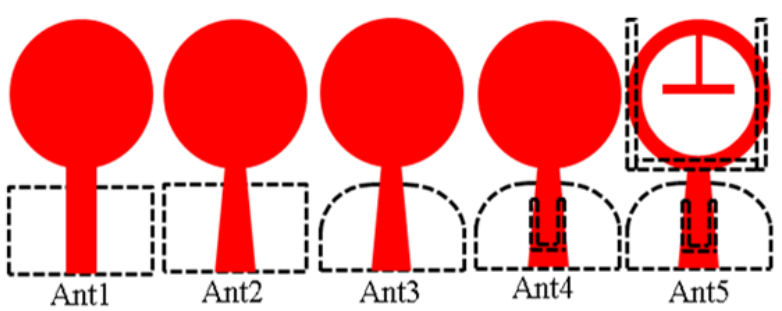

Fig. 2. Design evolution of the proposed DBN SWB PMA.

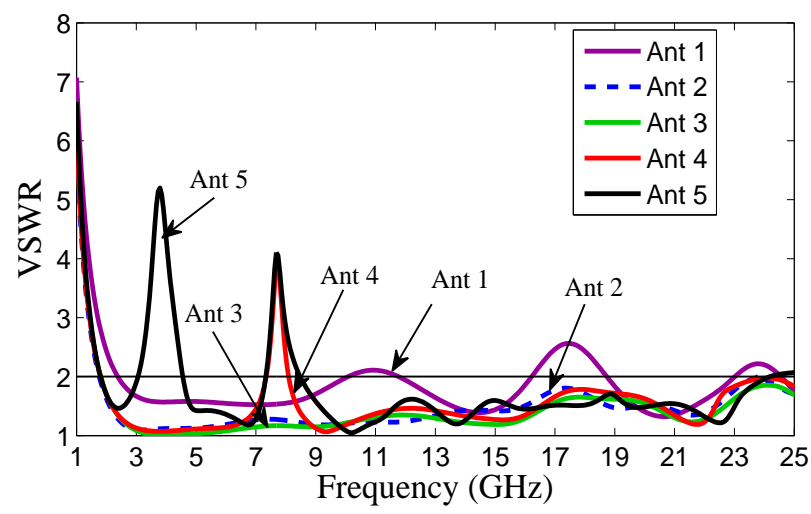

Fig. 3. Simulated VSWR of antennas 1-5. 


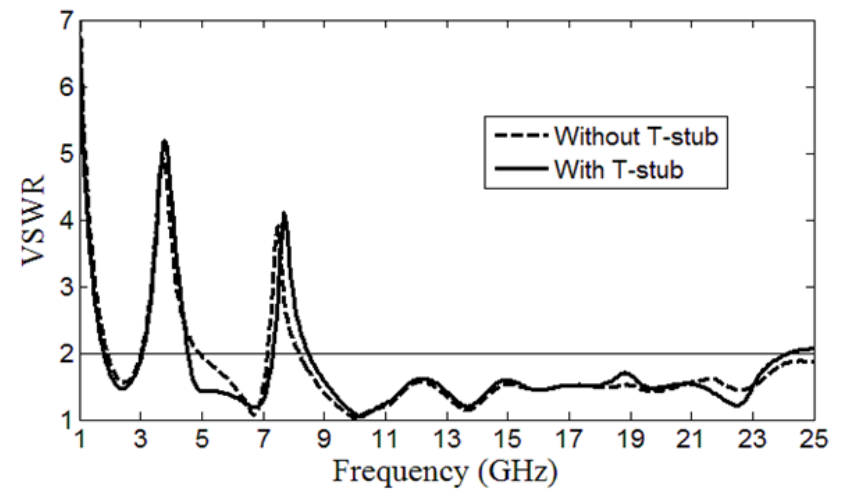

Fig. 4. Simulated VSWR versus frequency graph for the proposed compact DBN SWB PMA with and without inverted TSPS

The effect of inverted TSPS on the WiMAX/ C-band (3.2-4.4 GHz) and X-band satellite communication systems $(7.2-8.4 \mathrm{GHz})$ is shown in Fig. 4. It is found that without inverted TSPS, the upper edge frequency of WiMAX/C band increases from $4.4 \mathrm{GHz}$ to $4.9 \mathrm{GHz}$, while upper edge frequency of the X-band satellite communication systems decreases from 8.4 to $8.1 \mathrm{GHz}$, which does not cover the uplink frequency $(7.9-8.395 \mathrm{GHz})$ of X-band satellite communication systems. The widened frequency BW of WiMAX/C band notched characteristics $(3.2-4.9 \mathrm{GHz})$ unnecessarily blocks useful frequencies from 4.4 to $4.9 \mathrm{GHz}$.

To know more details about dual band-notched functionality of the proposed SWB antenna, parametric study has been carried out. Dual band-notched characteristics of the SWB antenna can be controlled mainly by the following parameters such as $R, W_{\mathrm{p}}$ and $L_{\mathrm{S}}$ for the radiating ring patch, U-shaped parasitic element and U-shaped slot respectively. Figure 5 depicts the simulated VSWR curves for different values of outer radius $R$ of circular ring patch. It can be observed that by increasing the value of $R$ from 8 to $9 \mathrm{~mm}$, the first notch band blocks deeper (amplitude of VSWR is about 6.5) within WiMAX/C-band, however center frequency of the second notch band (X-band) is shifted from 7.8 to $7.4 \mathrm{GHz}$ and also there is an impedance mismatch at higher frequencies (12-13 GHz and $16.5-18 \mathrm{GHz}$ ). When the position of $R=7 \mathrm{~mm}$, the impedance matching within SWB region is excellent, the center frequency of the first (WiMAX/Cband) and second (X-band) notched band is also appropriate. So the optimum value of $R=7 \mathrm{~mm}$. The simulated VSWR for different values of $W_{\mathrm{p}}$ (width of U-shaped parasitic element) is plotted in Fig. 6. In this arrangement by varying the value of $W_{\mathrm{p}}$ from 13.5 to $15.5 \mathrm{~mm}$, the center frequency of the second (X-band) notched band characteristics is insensitive; however the bandwidth of the first notch band (WiMAX/C-band) is decreased significantly. Therefore, the optimum value of $W_{\mathrm{p}}$ is decided to take $14.5 \mathrm{~mm}$.

Figure 7 shows the effect of the length $L_{\mathrm{S}}$ of U-shaped slot on the simulated VSWR curves. From Fig. 7 it can be found that, when the length $L_{\mathrm{S}}$ of U-shaped slot changes from $4.7 \mathrm{~mm}$ to $5.7 \mathrm{~mm}$, the center frequency of the second

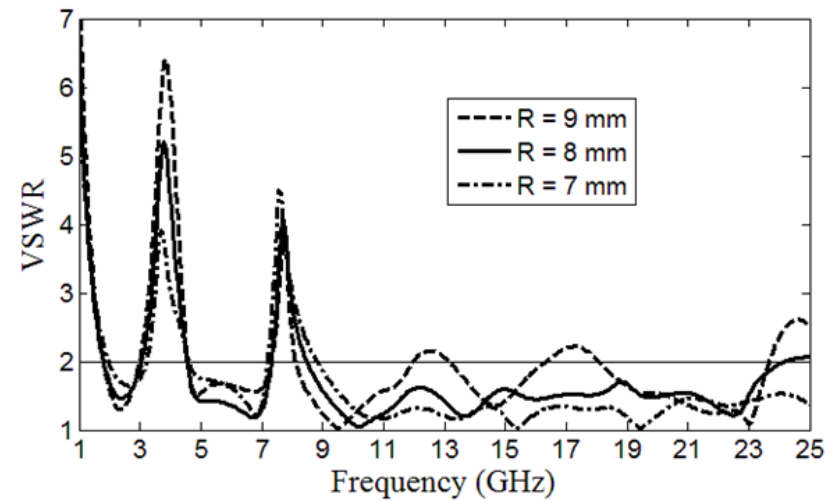

Fig. 5. Simulated VSWR versus frequency graph for the proposed compact SWB dual band-notched antenna with different value of $R$.

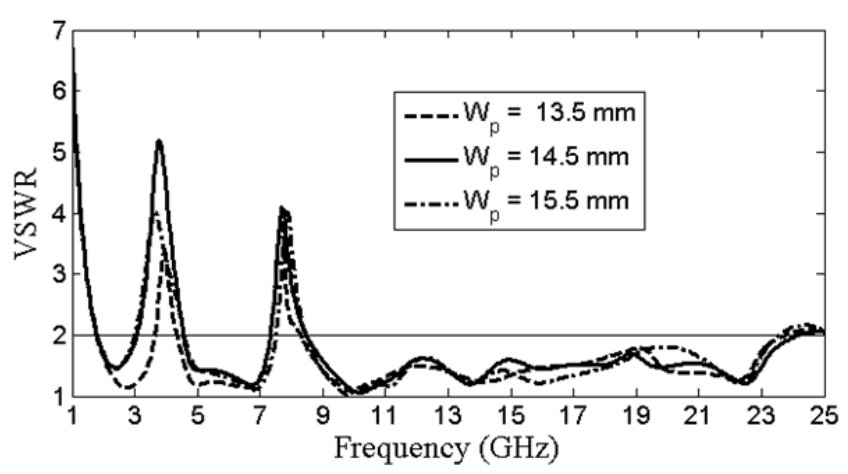

Fig. 6. Simulated VSWR versus frequency graph for the proposed compact SWB dual band-notched antenna with different value of $W_{\mathrm{p}}$.

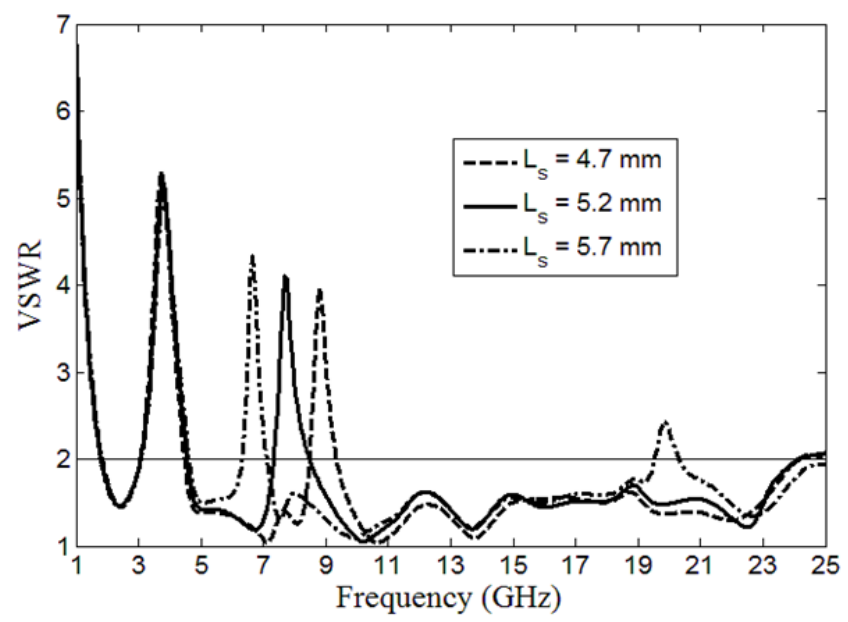

Fig. 7. Simulated VSWR versus frequency graph for the proposed compact SWB dual band-notched antenna with different value of $L_{\mathrm{S}}$.

notched band is varied from $9 \mathrm{GHz}$ to $6.5 \mathrm{GHz}$, however there is no variation within the first notched band region. Therefore the value of $L_{\mathrm{S}}$ has been selected to be $5.2 \mathrm{~mm}$, which controls the variable notched band with center frequency of $3.8 \mathrm{GHz}$.

Figure 8 (a) and (b) illustrates the simulated surface current distribution for the proposed SWB PMA at bandnotch center frequencies of 3.8 and $7.8 \mathrm{GHz}$. From Fig. 8(a) 


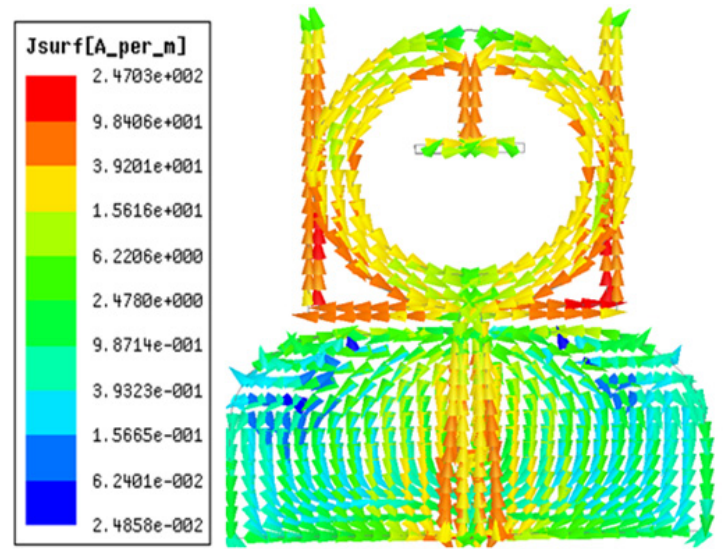

(a)

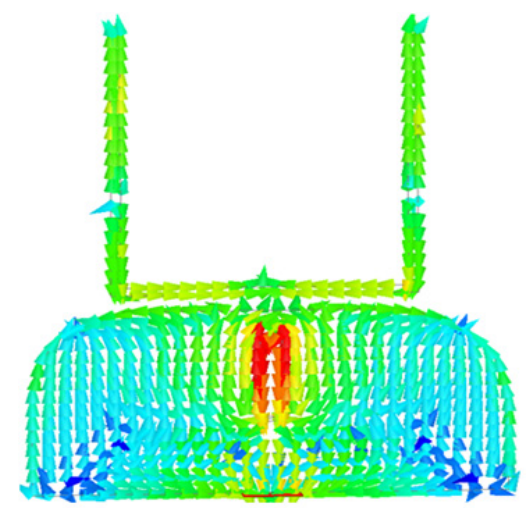

(b)

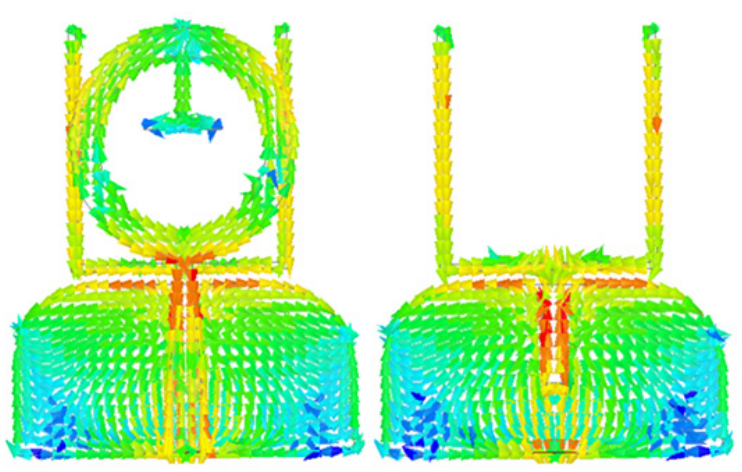

(c)

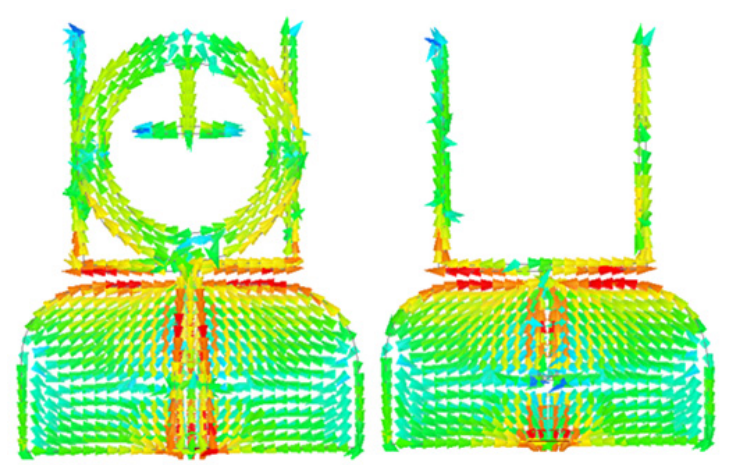

(d)

Fig. 8. Simulated surface current distributions: (a) $3.8 \mathrm{GHz}$ (front view), (b) $7.8 \mathrm{GHz}$ (back view), (c) $7 \mathrm{GHz}$ (front and back view), (d) $10 \mathrm{GHz}$ (front and back view).

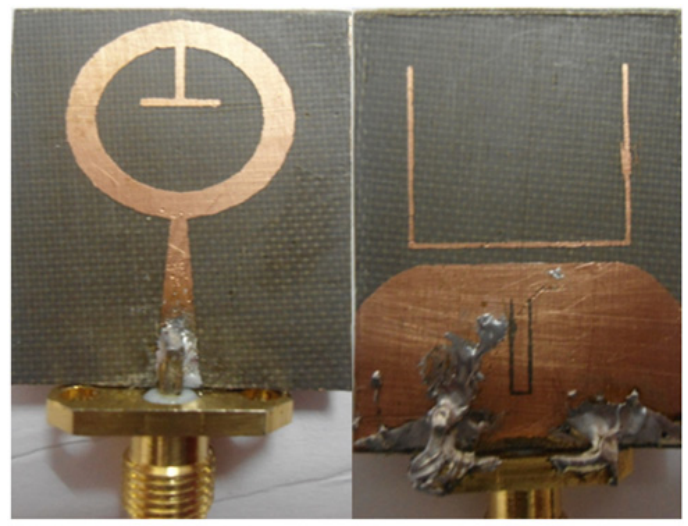

Front view

(a)

Bottom view

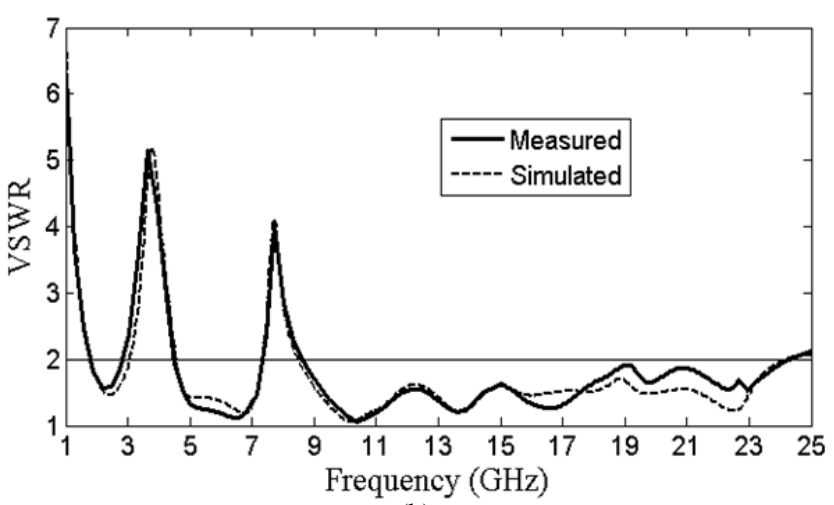

(b)

Fig. 9. (a) Image of the fabricated proposed DBN SWB PMA (b) simulated and measured VSWR versus frequency graph.

it is clearly seen that high current is gathered on the USPE around the $3.8 \mathrm{GHz}$ notched frequency and it is opposite in direction (out-of-phase) to the current flowing on the CR patch as well as inverted TSPS, which cancel out the effective radiation. Similarly, at frequency $7.8 \mathrm{GHz}$, it can be observed that strong current is crowded on USS and very small current is concentrated on the ground plane, which offers strong attenuation near the notch frequency $(7.8 \mathrm{GHz})$. It can be observed that small surface currents are flowing on both USPE and USS element at other frequencies such as $7 \mathrm{GHz}$ and $10 \mathrm{GHz}$ as depicted in Fig. 8(c) and (d) respectively.

Image of the fabricated antenna is shown in Fig. 9(a). The measurement is carried out with a Rohde and Schwarz ZVA24 vector network analyzer. Simulated and measured VSWR versus frequency graph for the proposed DBN SWB antenna is depicted in Fig. 9(b). Good agreement has been obtained up to $19 \mathrm{GHz}$ between simulation and experimental VSWR results, while small deviation can be observed between simulated results and measured one if frequency is higher than $19 \mathrm{GHz}$. This may be owing to the maximum suitable frequency for the SMA-connector is up to $18 \mathrm{GHz}$.

Figure 10 shows the simulated and measured gain radiation pattern of the proposed SWB PMA. It indicates that at low frequencies $(2.5$ and $10 \mathrm{GHz})$, the antenna has omni- 

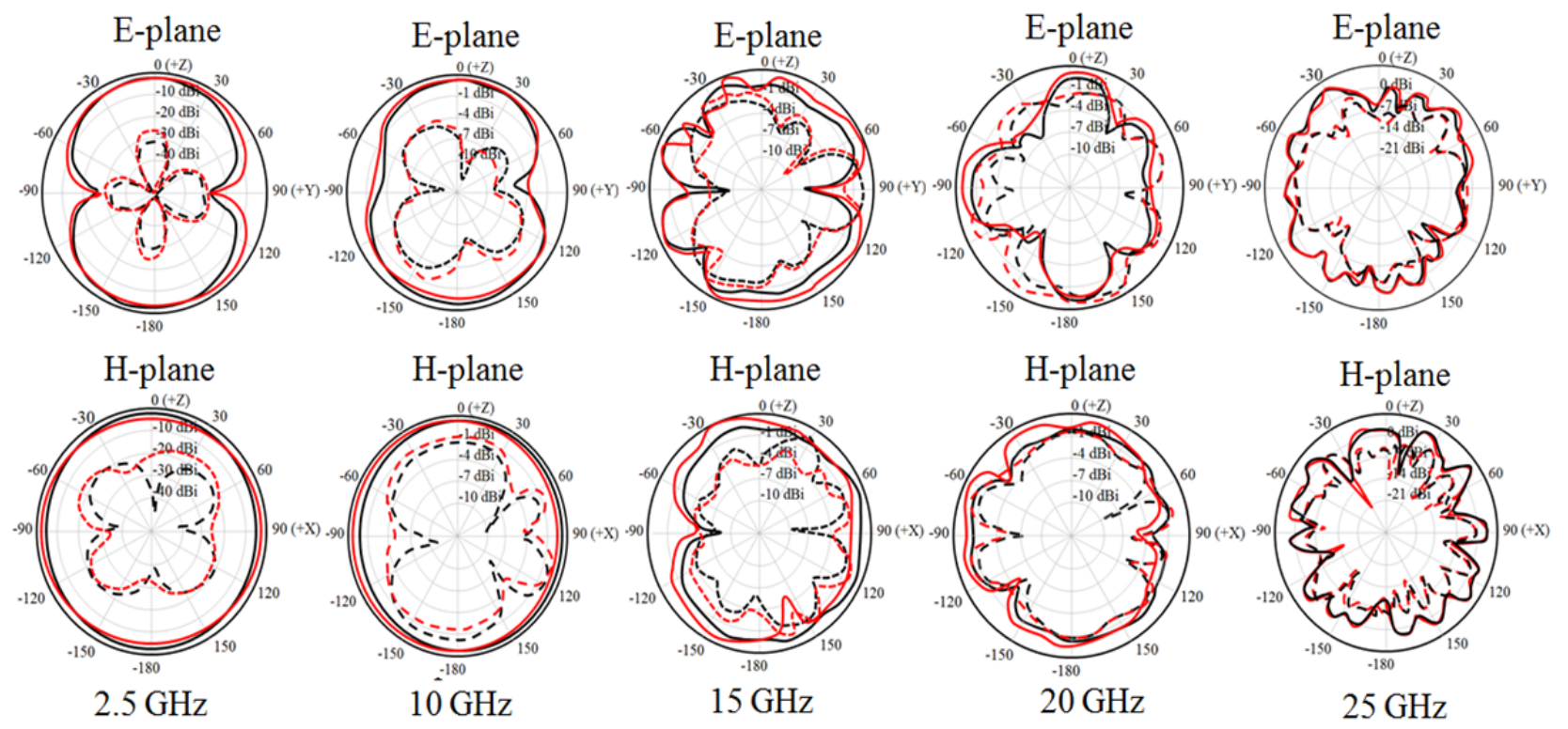

Fig. 10. Simulated (red) and measured (black) gain radiation pattern of DBN SWB PMA (solid line is co-polarization and dashed line is crosspolarization).

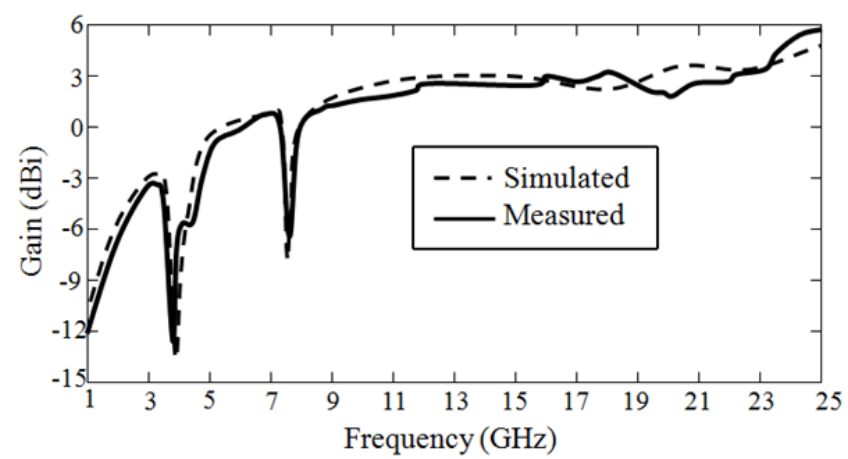

Fig. 11. Simulated and measured peak gain versus frequency graph for the proposed compact DBN SWB PMA.

\begin{tabular}{|c|c|c|c|}
\hline $\begin{array}{c}\text { Antenna of } \\
\text { ref. no. }\end{array}$ & $\begin{array}{c}\text { Dimensions } \\
(W \times L \times h) \mathrm{mm}^{3}\end{array}$ & RB & Substrate \\
\hline$[8]$ & $46.4 \times 38.5 \times 1$ & $6.25: 1$ & Not specified $\left(\varepsilon_{\mathrm{r}}=2.65\right)$ \\
\hline$[9]$ & $26 \times 32 \times 0.8$ & $3.93: 1$ & Rogers4003 $\left(\varepsilon_{\mathrm{r}}=3.38\right)$ \\
\hline$[10]$ & $30 \times 30 \times 1.6$ & $5.03: 1$ & FR4 $\left(\varepsilon_{\mathrm{r}}=4.4\right)$ \\
\hline$[11]$ & $24 \times 36 \times 1.524$ & $4.00: 1$ & Rogers4003 $\left(\varepsilon_{\mathrm{r}}=3.38\right)$ \\
\hline$[12]$ & $12 \times 18 \times 0.8$ & $4.59: 1$ & FR4 $\left(\varepsilon_{\mathrm{r}}=4.4\right)$ \\
\hline$[13]$ & $10 \times 16 \times 1.6$ & $6.17: 1$ & FR4 $\left(\varepsilon_{\mathrm{r}}=4.4\right)$ \\
\hline $\begin{array}{c}\text { Our } \\
\text { antenna }\end{array}$ & $24 \times 30 \times 0.787$ & $15.63: 1$ & $\begin{array}{c}\text { RT/Duroid5870 } \\
\left(\varepsilon_{\mathrm{r}}=2.23\right)\end{array}$ \\
\hline
\end{tabular}

Tab. 1. Comparison of the size and RB of the proposed DBN SWB PMA to DBN UWB antennas.

directional radiation pattern in the H-plane and bidirectional (eight shaped) patterns in the E-plane with negligible cross polarization. However, at the higher frequencies 15 , 20 and $25 \mathrm{GHz}$, the cross-polarization level rises in the $\mathrm{E}$ and H-planes, which is probably owing to the rising horizontal component of the surface currents on the radiating patch at higher frequencies. The simulated efficiency $\eta$ of the antenna varies from $82 \%-95 \%$ throughout SWB frequency except at the DBN frequency $\left(1^{\text {st }} \mathrm{BS} \eta \cong 65 \%\right.$ and $2^{\text {nd }} \mathrm{BS} \eta \cong 45 \%$ ). The simulated and measured peak gain versus frequency graph for the proposed DBN SWB PMA is shown in Fig. 11. From the graph, it can be observed that the peak gain of the proposed antenna is $5.8 \mathrm{dBi}$, while gain sharply drops in the vicinity of 3.8 and $7.8 \mathrm{GHz} \mathrm{BS}$. Table 1 depicts the dimension and RB of the proposed DBN SWB antenna with existing DBN UWB antennas. It can be observed that our proposed antenna has significantly larger RB than the antennas present in the published literature [8-13]. It also has smaller size than the DBN UWB antennas [8-11] except that of [12] and [13]. Note that DBN antennas of [12], [13] are designed on FR4 substrate which are meant for low frequency applications up to $2 \mathrm{GHz}$ [18]. FR4 substrate also has higher relative permittivity of 4.4 and size also depends on relative permittivity.

\section{Time Domain Performance}

The time domain performance is the significant characteristics of UWB antennas in which that is required to have least distortion in transmitting and receiving scenarios. To explore the time-domain characteristics of a bandnotched SWB antenna, two identical antennas were employed as transmitter and receiver. They are estranged from each other by a distance of $60 \mathrm{~cm}$ and placed in face-toface and side-by-side orientations. To act as a transmitter, one antenna is excited by a time-domain transient pulse, while the other one is a receiver.

A $5^{\text {th }}$ order derivative Gaussian input pulse waveform (generated in Tektronix AWG 7122B arbitrary signal generator) in the time domain with a width of $300 \mathrm{ps}$ and its power spectral density in frequency domain $(\mathrm{dBm} / \mathrm{MHz})$ with reference to federal communication commission (FCC) spectral mask are displayed in Fig. 12 and Fig. 13. The UWB short pulse reported in [19] is used to excite the proposed band-notched antennas is a fifth-order derivative of the Gaussian pulse and is given by 


$$
G_{5}(t)=A\left(-\frac{t^{5}}{\sqrt{2 \pi} \sigma^{11}}+\frac{10 t^{3}}{\sqrt{2 \pi} \sigma^{9}}-\frac{15 t}{\sqrt{2 \pi} \sigma^{7}}\right) \cdot \exp \left(-\frac{t^{2}}{2 \sigma^{2}}\right)(2)
$$

where $A$ is the amplitude parameter, $t$ is the time, and $\sigma$ is the standard deviation, whose value is $51 \mathrm{ps}$ to ensure that the shape of the spectrum fit inside the FCC spectral mask. The measured results suggest that the chosen fifth derivative of Gaussian pulse fits into the FCC spectral mask reasonably well, indicating that this UWB pulse complies with the FCC spectral mask.

Figure 14 and 15 plot the received pulse for face-toface and side-to-side configurations. It is seen that ringing distortion is observed in both the cases face-to-face and side-by-side scenarios, owing to the impedance mismatching at the notched bands. This confirms that the antenna does not response at all at the band-notched region. Moreover, it is also observed that the received signal amplitude is

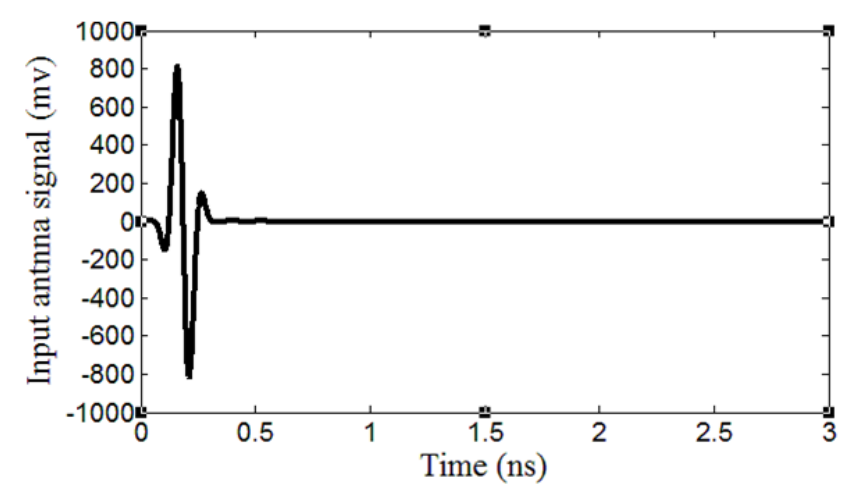

Fig. 12. Transmitted $5^{\text {th }}$ order derivative Gaussian input signal.

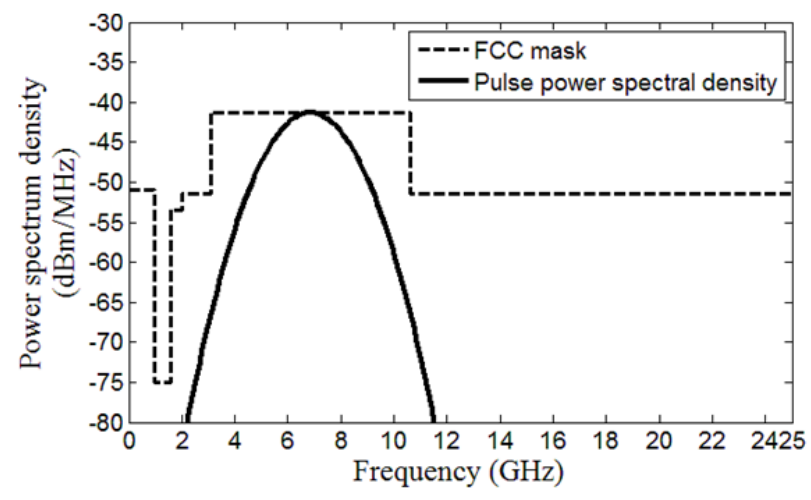

Fig. 13. Power spectral density.

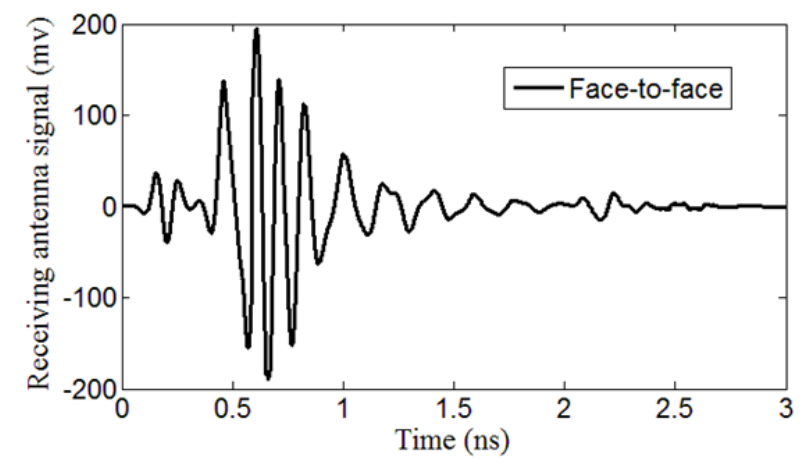

Fig. 14. Received signal in face-to-face scenario.

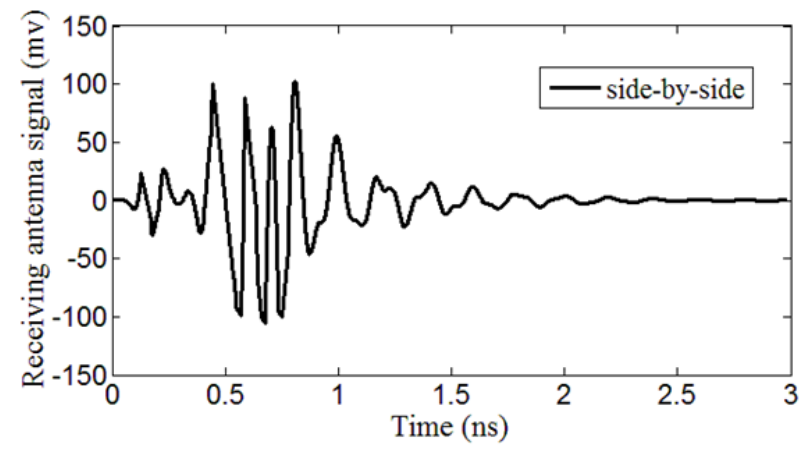

Fig. 15. Received signal in side-by-side scenario.

higher when two identical antennas are placed face-to-face $(200 \mathrm{mV})$ with respect to side-by-side $(100 \mathrm{mV})$ orientation. Overall ringing distortion is better than the existing UWB antennas in the literature [20]. To authenticate the similarity between received pulse $S_{2}(t)$ and transmitted or excited pulse $S_{1}(t)$ of the proposed antenna, the fidelity factor $\rho$ is calculated which is given as follows

$$
\rho=\max _{\tau}\left(\frac{\int S_{1}(t) S_{2}(t-\tau) \mathrm{d} t}{\sqrt{\int S_{1}^{2}(t) \mathrm{d} t} \sqrt{\int S_{2}^{2}(t) \mathrm{d} t}}\right)
$$

where $\tau$ is a delay which is varied to make numerator in (3) a maximum. Using (3), the fidelity factor is calculated to be 0.8521 when the two identical antennas were placed faceto-face scenario, and the value becomes 0.8132 when they were placed side-by-side scenario. It has been reported that the fidelity factor for UWB antenna [8] is $91.2 \%$ for faceto face-link.

\section{Conclusion}

A compact DBN SWB PMA has been proposed and investigated in this article. We have used TTMFL as well as RCFGP for broadband matching. The proposed SWB monopole antenna can operate from $1.6-25 \mathrm{GHz}$ (RB of $15.63: 1$ ), except in the DBN of $3.2-4.4 \mathrm{GHz}$ and $7.2 \mathrm{GHz}$ to $8.4 \mathrm{GHz}$. By employing USS and USPE, DBN characteristics have been obtained. The peak gain of the proposed antenna is $6 \mathrm{dBi}$, except in the DBN of $3.8 \mathrm{GHz}$ and $7.8 \mathrm{GHz}$.

\section{References}

[1] FCC, First report and order in the matter of revision of part 15 of the commission's rules regarding ultra-wideband transmission systems. Apr. 22 2002, p. 98-153. ISSN: 1937-8718.

[2] RUMSEY, V. Frequency Independent Antennas. New York: Academic Press, 1966. ISSN: 0018-926X

[3] CHEN, K. R., SIM, C., ROW, J. S. A compact monopole antenna for super wideband applications. IEEE Antennas and Wireless Propagation Letters, 2011, vol. 10, p. 488-491. ISSN: 1536-1225. DOI: 10.1109/LAWP.2011.2157071

[4] DONG, Y., HONG, W., LIU, L., ZHANG, Y., KUAI, Z. Performance analysis of a printed super-wideband antenna. Microwave 
and Optical Technology Letters, 2009, vol. 51, no. 4, p. 949-956. ISSN: 1098-2760. DOI: 10.1002/mop.24222

[5] DOROSTKAR, M. A., ISLAM, M. T., AZIM, R. Design of a novel super wide band circular-hexagonal fractal antenna. Progress In Electromagnetics Research, 2013, vol. 139, no. 4 p. 229-245. ISSN: 1070-4698. DOI: 10.2528/PIER13030505

[6] MANOHAR, M., KSHETRIMAYUM, R. S., GOGOI, A. K Printed monopole antenna with tapered feed line, feed region and patch for super wideband applications. IET Microwaves, Antennas and Propagation, 2014, vol. 8, no. 1, p. 39-45. ISSN: 1751-8725. DOI: 10.1049/iet-map.2013.0094

[7] WALADI, V., MOHAMMADI, N., ZEHFOROOSH, Y., HABASHI, A., NOURINIA, J. A novel modified star-triangular fractal (MSTF) monopole antenna for super-wideband applications. IEEE Antennas and Wireless Propagation Letters, 2013, vol. 12, p. 651 to 654. ISSN: 1536-1225. DOI: 10.1109/LAWP.2013.2262571

[8] LI, W. T., HEI, Y. Q., FENG, W., SHI, X. W. Planar antenna for 3G/Bluetooth/WiMAX and UWB applications with dual bandnotched characteristics. IEEE Antennas and Wireless Propagation Letters, 2012, vol. 11, p. 61-64. ISSN: 1536-1225. DOI: 10.1109/LAWP.2012.2183671

[9] JIANG, W., CHE, W. A novel UWB antenna with dual notched bands for WiMAX and WLAN applications. IEEE Antennas and Wireless Propagation Letters, 2012, vol. 11, p. 293-296. ISSN: 1536-1225. DOI: 10.1109/LAWP.2012.2190490

[10] SHOKRI, M., SHIRZAD, H., MOVAGHARNIA, S., VIRDEE, B., AMIRI, Z., ASIABAN, S. Planar monopole antenna with dual interference suppression functionality. IEEE Antennas and Wireless Propagation Letters, 2013, vol. 12, p. 1554-1557. ISSN: 1536-1225. DOI: 10.1109/LAWP.2013.2292921

[11] RYU, K., KISHK, A. UWB antenna with single or dual bandnotches for lower WLAN band and upper WLAN band. IEEE Transaction on Antennas and Propagation, 2009, vol. 57, no. 12, p. 3942-3950. DOI: 10.1109/TAP.2009.2027727

[12] OJAROUDI, M., OJAROUDI, N., GHADIMI, N. Dual bandnotched small monopole antenna with novel coupled inverted Uring strip and novel fork-shaped slit for UWB applications. IEEE Antennas and Wireless Propagation Letters, 2013, vol. 12, p. 182 to 185. ISSN: 1536-1225. DOI: 10.1109/LAWP.2013.2245296

[13] MEHRANPOUR, M., NOURINIA, J., GHOBADI, C., OJAROUDI, M. Dual band-notched square monopole antenna for ultrawideband applications. IEEE Antennas and Wireless Propagation Letters, 2012, vol. 11, p. 172-175. ISSN: 1536-1225. DIO: 10.1109/LAWP.2012.2186552

[14] POZAR, D. M. Microwave Engineering. John Wiley and Sons, 2005, p. 260. ISSN: 1931-7360. DOI: 10.1109/TAP.2003.816303

[15] MATHUR, S. P., SINHA, A. K. Design of microstrip exponentially tapered lines to match helical antennas to standard coaxial transmission lines. IEE Proceedings on Microwaves, Antennas and Propagation, 1988, vol. 135, no. 4, p. 272-274. ISSN: 0950-107X. DOI: 10.1049/ip-h-2.1988.0055.

[16] CHEN, Z. N., SEE, T. S., and QING, X. Small printed ultrawideband antenna with reduced ground plane effect. IEEE Transactions on Antennas and Propagation, 2007, vol. 55, p. $383-$ 388. ISSN: 0018-926X. DOI: 10.1109/TAP.2006.889823

[17] DONG, Y., HONG, W., LIU, L., ZHANG, Y., KUAI, Z. Performance analysis of a printed super-wideband antenna Microwave and Optical Technology Letters, 2009, vol. 51, no. 4, p. 949-956. ISSN: 1098-2760. DOI: 10.1002/mop.24222

[18] HUANG, Y., BOYLE, K. Antennas from Theory to Practice, Wiley, 2008, p. 64.

[19] KIM, H., PARK, D., JOO, Y. All-digital low-power CMOS pulse generator for UWB system. Electronics Letter, 2004, vol. 40, no. 24 , p. $1534-1535$. DOI: $10.1049 /$ el.20046923
[20] GAO, G., HU, B., CONG, X., HE, L. Investigation of a novel dual band-notched UWB antenna by the equivalent circuit model and time domain characteristics. Microwave and Optical Technology Letters, 2013, vol. 55, no. 12, p. 2993-3000. ISSSN: 1096-4290. DOI: $10.1002 /$ mop. 27948 .

\section{About the Authors ...}

Murli MANOHAR was born in Bhagalpur, India in 1984. He received the Ph.D. degree in Electronics and Electrical Engineering from the Indian Institute of Technology Guwahati, India in April 2015. He is presently working as an assistant professor in the Dept. of Electronics and Communication Engineering, Indian Inst. of Information Technology Manipur, India. His main research area is in antenna and RF engineering with focus on SWB printed monopole antenna.

Rakhesh Singh KSHETRIMAYUM received the Ph.D. degree from the School of Electrical and Electronic Engineering (EEE), Nanyang Technological University (NTU) Singapore in 2005. Since 2005, he has been with the Dept. of EEE, IIT Guwahati as an Associate Professor (2010-), Assistant Professor (2006-10) and Senior Lecturer (20052006). He worked as a Postdoctoral Scholar at the Dept. of EE, Pennsylvania State University (PSU), USA (2005), Research Associate Provisional at the Dept. of Electrical Communication Engineering (ECE), Indian Inst. of Science (IISc) Bangalore (2004-2005), Teaching Assistant at the School of EEE, NTU Singapore (2002-2003) and Trainee Software Engineer at Mphasis, India (2000-2001). Dr. Kshetrimayum is the recipient of SEFOGG Young Engineer Award (2011), Dept. of Science \& Technology India (SERC) Fast Track Scheme for Young Scientists (20072010) and NTU Research Scholarship from 2001-2004. His current areas of research interests are in printed antennas and circuits, UWB communications and MIMO wireless communications. He has been involved in organizing several IEEE international conferences as Technical program co-chair, Publication chair, Program chair, Session chair and Technical program committee. He is the Editor-inChief of Inderscience journal International Journal of Ultra Wideband Communications and Systems. He is a Life Fellow of the Institution of Electronics and Telecommunication Engineers (IETE), India, Optical Society of India (OSI) and Antenna Test \& Measurement Society (ATMS), India; a senior member of the International Association of Computer Science and Information Technology (IACSIT), Singapore, and the Inst. of Electrical and Electronics Engineers (IEEE), USA; a member of the Applied Computational Electromagnetics Society (ACES), USA and the European Microwave Association (EuMA), Belgium.

Anup Kumar GOGOI is a Professor of Electronics and Electrical Engineering and Dean of Outreach Education Programme at the Indian Institute of Technology Guwahati. He received his Ph.D. degree from the Dept. of Electrical Engineering, Indian Inst. of Technology Kanpur. His areas of research interests are in electromagnetics, microwave engineering, RF circuits and systems design. 